\title{
Vesta Sarkhosh Curtis, M. Elahé Askari, Elizabeth J. Pendleton with Richard Hodges, Ali-Akbar Safi. Sasanian Coins. A Sylloge of the Sasanian Coins in the National Museum of Iran (Muzeh Melli Iran), Tehran. Vol. 1. Ardashir I - Hormizd IV, Vol. 2. Khusrau II - Yazdgard III
}

Rika Gyselen

\section{CpenEdition Journals}

Édition électronique

URL : http://journals.openedition.org/abstractairanica/42358

DOI : 10.4000/abstractairanica.42358

ISSN : 1961-960X

Éditeur :

CNRS (UMR 7528 Mondes iraniens et indiens), Éditions de l'IFRI

Référence électronique

Rika Gyselen, « Vesta Sarkhosh Curtis, M. Elahé Askari, Elizabeth J. Pendleton with Richard Hodges, Ali-Akbar Safi. Sasanian Coins. A Sylloge of the Sasanian Coins in the National Museum of Iran (Muzeh Melli Iran), Tehran. Vol. 1. Ardashir I - Hormizd IV, Vol. 2. Khusrau II - Yazdgard III », Abstracta Iranica [En ligne], Volume 34-35-36 | 2017, document 64, mis en ligne le 30 juillet 2017, consulté le 05 octobre 2020. URL : http://journals.openedition.org/abstractairanica/42358 ; DOI : https://doi.org/10.4000/ abstractairanica. 42358 
Vesta Sarkhosh Curtis, M. Elahé Askari, Elizabeth J. Pendleton with Richard Hodges, Ali-Akbar Safi. Sasanian Coins. A Sylloge of the Sasanian Coins in the National Museum of Iran (Muzeh Melli Iran), Tehran. Vol. 1. Ardashir I - Hormizd IV, Vol. 2. Khusrau II - Yazdgard III

Rika Gyselen

\section{RÉFÉRENCE}

Vesta Sarkhosh Curtis, M. Elahé Askari, Elizabeth J. Pendleton, Richard Hodges, AliAkbar Safi. Sasanian Coins. A Sylloge of the Sasanian Coins in the National Museum of Iran (Muzeh Melli Iran), Tehran. Vol. 1. Ardashir I - Hormizd IV, Vol. 2. Khusrau II - Yazdgard III. Londres, Royal Numismatic Society \& British Institute of Persian Studies, vol. 1, 2010, 102 p. + 102 planches et vol. 2, 2012, 352 p. + 352 planches.

1 Avec quelque 4400 monnaies, ces deux volumes constituent une addition appréciable au corpus des monnaies sassanides en général, et à la Sylloge Nummorum Sasanidarum en particulier.

2 L'ouvrage se limite à une pure sylloge: un catalogue avec une description de chaque monnaie (page de gauche) et une reproduction photographique (page de droite) dont on peut apprécier la très bonne qualité. L'absence d'index rend les volumes peu adaptés 
à des recherches ponctuelles. On peut regretter que l'ordre dans le catalogue soit aléatoire. Contrairement à d'autres collections dont chaque pièce a été choisie par un conservateur, cette collection est plutôt le résultat du hasard et reflète la production monétaire courante.

Il est quelque peu superflu de formuler d'autres observations - en particulier sur le volume 1 - puisque H. M. Malek y a consacré un article de synthèse auquel on se réfèrera : H. M. Malek, Review article : « Sasanian Numismatic Research in the Context of the Muzeh Melli Iran », The Numismatic Chronicle, 171, 2001, p. 469-486. Ce dernier attire l'attention sur le petit nombre de contrefaçons dans cette collection puisque peu de monnaies ont été acquises auprès de collectionneurs ou d'antiquaires. Cet article qui fait parfois office d'index du volume 1 , fourmille de remarques pertinentes.

4 Voir également le c.r. n 199 d'AI 32-33 sur le $1^{\text {er }}$ vol. de cet ouvrage publié en 2010

\section{AUTEURS}

\section{RIKA GYSELEN}

CNRS, Mondes iranien et indien 